\title{
Incidence and Clinical Manifestations on Diabetes Mellitus in Canines
}

\author{
Shashi Choudhary*, Nazeer Mohammed, Rashmi Singh, Jitendra Kant Nagar, \\ Chanchal Kala, Amit Kumar Meena, Raj Kumar Soni, Praveen Meena \\ and Kiran Choudhary
}
Department of Veterinary Medicine, Institute of Veterinary Education and Research (PGIVER), Jaipur, RAJUVAS, Bikaner 334001 Rajasthan, India

*Corresponding author

Keywords

Jaipur, Diabetes Mellitus, Incidence, clinical manifestations, Polydipsia, Polyuia

Article Info

Accepted:

20 June 2021

Available Online:

10 July 2021

\section{A B S T R A C T}

The present study was conducted to determine the incidence and record clinical manifestations in Jaipur region, of Rajasthan during June, 2020 to December, 2020. A total of two hundred canines of different age group, sex and breed with the history of polydipsia, polyphagia, polyuria, obesity, rapidly developing bilateral cataracts, rapid weight loss or in combination thereof were screened. Blood samples of canines suspected for diabetes mellitus were screened for blood glucose by using on-site glucometer. Canines showing fasting blood glucose level > $140 \mathrm{mg} / \mathrm{dl}$, were included for the present study. On the bases of screening test results, eleven canines were diagnosed as diabetic. The overall incidence of diabetes mellitus in canines was recorded 5.5 per cent. Breed wise incidence of DM found highest in labrador breed. Age-wise incidence of DM was highest in >6 years of age. Sex wise incidence of DM in canines was higher in females as compared to males, respectively. Polydipsia, polyuria and weight loss were the most frequently found clinical signs in majority of diabetic canines.

\section{Introduction}

The word 'diabetes' is derived from the Greek word "Diab" (meaning to pass through, referring to the cycle of heavy thirst and frequent urination); 'mellitus' is the Latin word for "sweetened with honey" (refers to the presence of sugar in the urine). Greeks had the knowledge of a disease accompanied by polyuria and wasting of body, whereas 
Arelacus of Cappadocia mentioned a disease characterized by thirst and polyuria. From the Middle East, the knowledge of diabetes mellitus had spread to Spain as a disease characterized by polyuria, polydipsia with sugary flavoured urine. With the discovery of sugar in urine and its detection by laboratory test, the knowledge permeated into the $18^{\text {th }}$ century (Patel et al., 2012).

Diabetes is a common disease affecting human health and life quality. The incidence of diabetes ranks the second following cancer. In the year 2000, the global prevalence of diabetes for all age groups was estimated to 2.8 per cent of the population. Recent World Health Organisation (WHO) calculations indicate that almost 3 million deaths per year worldwide are attributable to diabetes mellitus(DM) and the numbers of affected persons are estimated to be doubled by the year 2030, solely taking into account the demographic changes (WHO, 2011).

Diabetes mellitus is a group of metabolic diseases characterized by hyperglycemia resulting from defects in insulin secretion, insulin action or both (Groop and Pociot, 2013). Diabetes mellitus is characterized by rise of blood glucose levels (hyperglycemia), passing of glucose (glucosuria) and ketone bodies (ketonuria) in urine, deficiency or inability to utilize insulin for the normal metabolism of carbohydrates, proteins and fats (Pugh and Baird, 2012).

Screened 251 dogs of different breeds and reported 10.88 per cent incidence of diabetes at Indian Veterinary Research Institute, Izatnagar. Diabetes mellitus was confirmed on the basis of random blood sugar and relevant clinical parameters.

Also opined that diabetes mellitus may occur in any dog, the disease is however, shown in several studies to be more frequently occurring in females than in males, in older dogs than in younger, and in some breeds more than others (Kumar et al., 2014).

\section{Materials and Methods}

\section{Screening of animals}

A total of two hundred canines of different age, sex and breed with the history of polydipsia, polyphagia, polyuria, obesity, rapidly developing bilateral cataracts, rapid weight loss or in combination thereof were screened. Blood samples of canines suspected for diabetes mellitus were screened for blood glucose by using on-site glucometer. The canines showing random blood glucose level above $140 \mathrm{mg} / \mathrm{dl}$, were tested for fasting blood glucose next day after 12 hours of fast (Jatav, 2015) and those canines showing fasting blood glucose level above $140 \mathrm{mg} / \mathrm{dl}$, were included for the present study.

\section{Incidence}

Based on the evaluations of screening using different tests, the incidence of diabetes mellitus was determined across:

Overall incidence of diabetes mellitus in canine

With relation to breed

Different age groups

\section{Different sex groups}

\section{Collection of blood and serum}

In order to study haemato-biochemical alterations in diabetic canines, blood samples were collected from all canines following all the aseptic precautions. Using 22 or 24 gauge sterilized needle and 10 milliliter (ml) disposable syringe, total $7 \mathrm{ml}$ of blood was 
collected from the cephalic or saphenous vein. Out of this, $2 \mathrm{ml}$ blood was collected in sterilized test tubes containing disodium salt of ethylene diamine tetra acetic acid (EDTA) @ $1 \mathrm{mg} / \mathrm{ml}$ of blood) as an anticoagulant while remaining $5 \mathrm{ml}$ blood was collected in another sterilized test tube without any anticoagulant for the separation of serum and thereafter blood slants were made and incubated for one hour at $30^{\circ} \mathrm{C}$. Then the tubes were refrigerated for some time (allowing retraction of clot) and centrifuged at 2500 rhythm per minute (rpm) for 30 minutes in order to separate serum. On separation, serum was immediately transferred into sterilized screw capped vial; a drop of Merthiolate solution $(1: 10,000)$ was added and stored in deep freeze at $-40{ }^{\circ} \mathrm{C}$ until used for biochemical estimations.

The blood samples were also collected from 10 healthy canine (Healthy control group) as described above and subjected for the estimation of haematological and biochemical values.

\section{Collection of urine}

About 5-10 $\mathrm{ml}$ of urine was collected in a clean, dry container either during spontaneous urination by following the necessary precautions or by catheterization. Urine samples were collected aseptically in test tubes directly and/or centrifuged for 20 minutes to remove insoluble impurity and cell debris at $1000 \mathrm{rpm}$ at $2-8^{\circ} \mathrm{C}$. Clear supernatant of urine was collected in small pyrex tubes for routine urinalysis using dip-stick and was refrigerated immediately until analysis.

\section{Clinical Diagnosis}

Clinical diagnosis was carried out through history, clinical manifestations, clinical examinations, biochemical estimations and laboratory tests for blood glucose. Blood samples were collected from all affected canines and assayed for different laboratory tests. Urine samples were also collected for routine urinalysis using dip-stick. Urine and blood samples were collected again 7 days post treatment to evaluate the response of therapy. The various techniques applied in relation to sampling procedure and laboratory investigations for confirmation of diagnosis.

\section{Results and Discussion}

\section{Overall incidence of diabetes mellitus in canines}

The overall incidence of diabetes mellitus in canines was found to be 5.5 per cent. Kumar et al., (2014) and Shruthi (2016) reported higher incidence of 10.88 and 10.00 per cent, respectively in diabetes mellitus affected canines. However, Deepa et al., (2014), Mattin et al., (2014), Nelson and Reusch (2014) and kapoor (2019) reported low incidence rate of $0.6,0.34,0.4$ to 1.2 and 0.99 per cent, respectively.

Various other possible inflicting factors contributing to increased incidence of DM are urbanization of human population and engagement in occupations ensuing change in lifestyle of pet dogs, more dependence on commercial pet food, lack of exercise, uncontrolled feeding or high fat pet foods, preference for breeds predisposed to DM (Klinkenberg et al., 2006).

\section{Incidence of diabetes mellitus in relation to breed}

It was found that breed wise incidence of diabetes mellitus in canines was highest in labrador breed $(36.36 \%)$, followed by spitz (18.18\%), pug (18.18\%), pomeranian $(9.09 \%)$, german shepherd $(9.09 \%)$ and rottweiler (9.09\%), respectively. Which is agreement with our observations, Deepa et al., (2014). 
Shruthi, (2016) also reported that labrador breed was found to be higher in number in study.

Major histocompatibility complex (MHC) class II is responsible for presenting antigen to $\mathrm{T}$ lymphocyte. Some DLA genes are monomorphic and others loci are polymorphic in canines.

Therefore, depending on variation in gene pool of DLA, the susceptibility to autoimmune disease varies and so the breed predisposition to canine DM (Kumar et al., 2014).

\section{Incidence of diabetes mellitus in relation to the age}

Present investigation results revealed that agewise incidence of diabetes mellitus in canines was highest in $>6$ years of age $(54.54 \%)$, followed by 1-6 years of age (36.36\%) and $<1$ year of age $(9.09 \%)$, respectively. Our study reveals higher Incidence of DM in dogs which are more than six years of age which is also supported by several authors (Davison et al., 2005, Catchpole et al., 2005 and Deepa et al., 2014). These authors reported higher incidence in older canines (dogs).

The probable reason was suggested to be insulin resistance which was observed in adult canine diabetes mellitus cases and was attributed to exogenous corticosteroids, progestagen treatment or endocrinopathies like hyperadrenocorticism and hypothyroidism (Hess et al., 2000).

\section{Incidence of diabetes mellitus in relation to the sex}

Present investigation results revealed that sexwise incidence of diabetes mellitus in canines was higher in females $(63.63 \%)$ as compared to males (36.36\%), respectively. Similar findings were also reported by Catchpole et al., (2005), Fall et al., (2007) and Das and Lodh (2015) who has reported 53 per cent, 72 per cent and 73.3 per cent females in their study, respectively. Herrtage (2009), Kumar et al., (2014) and Shruthi (2016) also reported that female dogs were found to be more affected with diabetes mellitus.

Entire females are more frequently affected than males and this is mainly due to induction of growth hormone secretion by progesterone and other progestogens (Herrtage, 2009).

\section{Clinical manifestations of diabetes mellitus in canines}

In the present study, clinical findings recorded in diabetes mellitus affected canines were polydipsia $(81.81 \%)$, polyphagia $(63.63 \%)$, polyuria $(72.72 \%)$, weight loss $(72.72 \%)$, vomiting (18.18\%) and cataract formation (27.27\%). Clinical findings recorded in the present study are similar to those reported by Hess et al., (2000), Guptill et al., (2003), Herrtage (2009), Rucinsky et al., (2010) and Kumar et al., (2014).

Diabetes mellitus results from a absolute deficiency of insulin secretion by the $\beta$ cells, insulin deficiency in turn causes decreased tissue utilization of glucose, amino acid and fatty acids, accelerated hepatic glycogenolysis, gluconeogenesis and accumulation of glucose in the circulation, causing hyperglycemia, as the blood glucose concentration causing hyperglycemia. As the blood glucose concentration increases, the ability of the renal tubular cells to resorb glucose from the glomerular ultra filtrate is exceeded resulting in glycosuria in dogs, when blood glucose concentration exceed $180 \mathrm{mg} / \mathrm{dL}$ to $220 \mathrm{mg} / \mathrm{dl}$ glycosuria creates an osmatic diuresis with compensatory polyuria and in turn polydipsia. 
Table.1 Overall incidence of diabetes mellitus in canines.

\begin{tabular}{|c|c|c|}
\hline $\begin{array}{c}\text { Total no. of canines } \\
\text { screened }\end{array}$ & $\begin{array}{c}\text { No. of canines affected with } \\
\text { diabetes mellitus }\end{array}$ & $\begin{array}{c}\text { Percentage of canines } \\
\text { affected with diabetes } \\
\text { mellitus }\end{array}$ \\
\hline 200 & 11 & $5.5 \%$ \\
\hline
\end{tabular}

Table.2 Incidence of diabetes mellitus with relation to breed

\begin{tabular}{|c|c|c|c|}
\hline S. No. & Breed & No. of positive cases (11) & Percentage (\%) \\
\hline 1 & Labrador & 4 & $36.36 \%$ \\
\hline 2 & Spitz & 2 & $18.18 \%$ \\
\hline 3 & Pomeranian & 1 & $9.09 \%$ \\
\hline 4 & German shepherd & 1 & $9.09 \%$ \\
\hline 5 & Rottweiler & 1 & $9.09 \%$ \\
\hline 6 & Pug & 2 & $18.18 \%$ \\
\hline
\end{tabular}

Table.3 Incidence of diabetes mellitus in different age groups

\begin{tabular}{|c|c|c|c|}
\hline $\begin{array}{c}\text { S. } \\
\text { No. }\end{array}$ & Age (Years) & No. of positive cases (11) & Percentage (\%) \\
\hline 1 & $<1$ year & 1 & $9.09 \%$ \\
\hline 2 & $1-6$ years & 4 & $36.36 \%$ \\
\hline 3 & $>6$ years & 6 & $54.54 \%$ \\
\hline
\end{tabular}

Table.4 Incidence of diabetes mellitus in relation to the sex.

\begin{tabular}{|c|c|c|c|}
\hline S. No & Sex & No. of positive cases (11) & Percentage (\%) \\
\hline 1 & Male & 4 & $36.36 \%$ \\
\hline 2 & Female & 7 & $63.63 \%$ \\
\hline
\end{tabular}

Table.5 Major clinical manifestations recorded from canines affected with diabetes mellitus.

\begin{tabular}{|c|c|c|c|}
\hline S. No. & Clinical manifestation & $\begin{array}{c}\text { Numbers of positive cases } \\
\text { showed (11) }\end{array}$ & Percentage (\%) \\
\hline 1 & Polydipsia & 9 & $81.81 \%$ \\
\hline 2 & Polyphagia & 7 & $63.63 \%$ \\
\hline 3 & Polyuria & 8 & $72.72 \%$ \\
\hline 4 & Weight loss & 8 & $72.72 \%$ \\
\hline 5 & Vomiting & 2 & $18.18 \%$ \\
\hline 6 & Cataract formation & 3 & $27.27 \%$ \\
\hline
\end{tabular}


Picture.1 Cataract formation and weight loss along with emaciation in diabetic dog

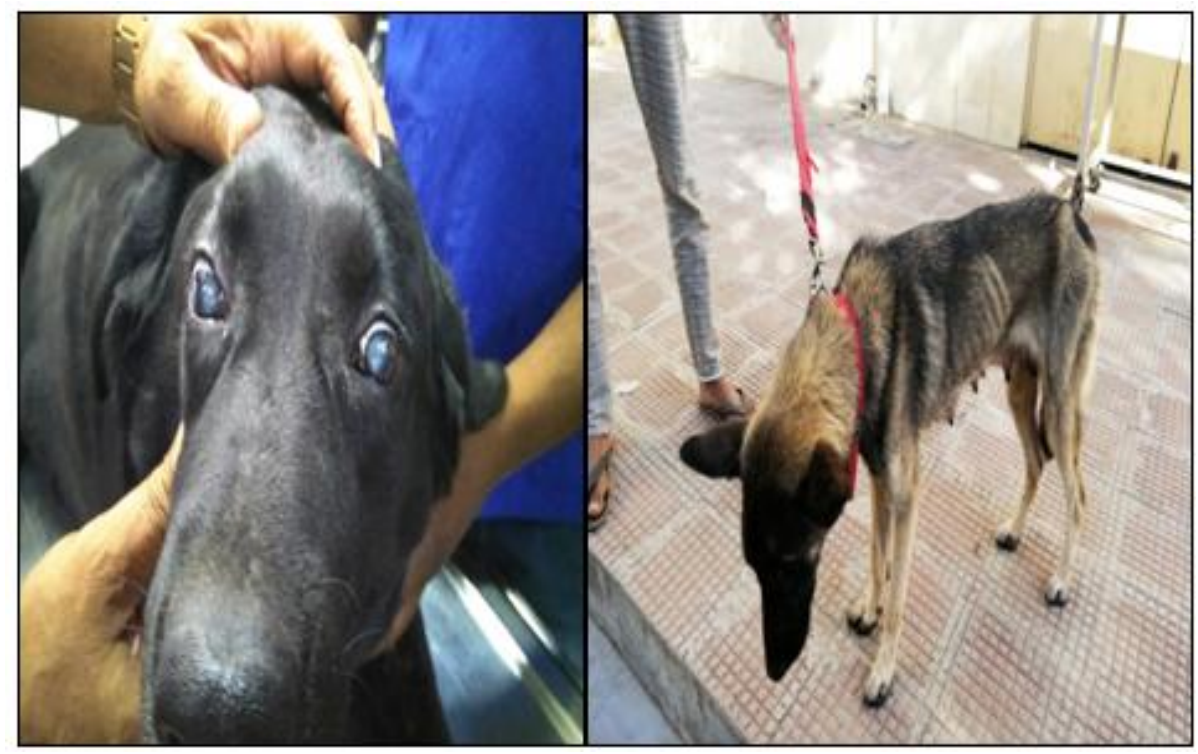

Diminished peripheral tissue utilization of ingested glucose result in weight loss as the body attempts to compensate for perceived starvation. The feeding center responsible for evoking eating behavior continuously function but can be transiently inhibited by the satiety center after food ingestion.

The amount of glucose entering the cells in the satiety center directly affects the feeling of hunger, the more glucose that enters these cells, the less feeling of hunger. The ability of glucose to enter the cells in the satiety center is mediated by insulin. In diabetics with a relative lack of insulin, glucose does not enter satiety center cells, resulting in failure to inhibit the feeding center. Thus it become polyphagic condition (Ettinger and Feldman, 2010).

\section{Acknowledgements}

Department of Veterinary Medicine, Post Graduate Institute of Veterinary Education and Research (PGIVER), Jaipur and Government Veterinary Polyclinic Hospital, Panchbatti, Jaipur.

\section{References}

Catchpole, B., Ristic, J. M., Fleeman, L. M. and Davison, L. J. 2005. Canine diabetes mellitus can old dogs teach us new tricks? Diabetologia. 48(10):1948-1956.

Das, S. and Lodh, C. 2015. Epidemiology of canine diabetes mellitus in west Bengal. Indian J. Can. Pract. 7(1):66.

Davison, L. J., Herrtage, M. E. and Catchpole, B. 2005. Study of 253 dogs in the United Kingdom with diabetes mellitus. Veterinary Record. 156:467-471.

Deepa, P. M., Dimri, U., Jhambhi, R., Ramees, T. P., Vijaykumar, H., Gopinath, D., Mahendran, K. and Mondal, D. B. 2014. Secondary subclinical diabetes mellitus in dogs infected with. Ehrlichiacanis. Int. J. Adv. Res. 2(1):858-863.

Ettinger, S. J. and Feldman, E. C. 2010. Textbook of Veterinary Internal Medicine. $7^{\text {th }}$ Edition. Elsevier, St. Louis, Missouri. pp 1449-1474.

Fall, T., Hamlin, H. H., Hedhammar, A., Kampe, O. and Egenvall, A. 2007. Diabetes mellitus in a population of 180,000 insured dogs: incidence, survival, and breed distrib ution. Journal of Veterinary Internal Medicine. 21:1209- 
1216.

Groop, L. and Pociot, L. 2013. Genetics of diabetes- are we missing the genes or the disease? Molecular and cellular endocrinology. 382(1):726-739.

Guptill, L., Glickman, L. and Glickman, N. 2003. Time trends and risk factors for diabetes mellitus in dogs: Analysis of veterinary medical data base records (1970-1999). The Veterinary Journal. 165:240-247.

Herrtage, M. E. 2009. Proceedings of the $34^{\text {th }}$ world small animal veterinary Congress. WSAVA Med. 41:177-184.

Hess, R. S., Saunders, H. M., Winkle, T. J. and Ward, C. R. 2000. Concurrent disorders in dogs with diabetes mellitus: 221 cases (1993-1998). Journal of the American Veterinary Medical Association. 217:1166-1173.

Jatav, R. S. 2015. Screening of dogs for diabetes mellitus in gwalior and vidisha districts of Madhya Pradesh and role of antioxidant in experimental diabetes. $\mathrm{PhD}$ thesis submitted to Indian Veterinary Research Institute, Izatnagar. Pp 1-78.

Kapoor, S. 2019. Clinico therapeutic studies on canine diabetes mellitus. M.V.Sc. thesis submitted to Chaudhary Sarwan Kumar Himachal Pradesh Krishi Vishvavidyalaya, Palampur. pp 1-110.

Klinkenberg, H., Sallander, M. H. and Hedhammar, A. 2006. Feeding, exercise, and weight identified as risk factors in canine diabetes mellitus. The Journal of Nutrition. 136:1985-1987.

Kumar, P., Kumari, R. R., Kumar, M., Kumar, S. and Chakrabarti, A. 2014. Current practices and research updates on diabetes mellitus in canine. Veterinary World. 7:952-959.

Mattin, M., O'neill, D., Church, D., McGreevy, P. D., Thomson, P. C. and Brodbelt, D. 2014. An epidemiological study of diabetes mellitus in dogs attending first opinion practice in the U.K. Veterinary Record. 174(14):349-349.

Nelson, R. W.and Reusch, C. E. 2014. Classification and etiology of diabetes in dogs and cats. Journal of Endocrinology. 222: T1-T9.

Patel, D. K., Kumar, R., Laloo, D. and Hemalatha, S. 2012. Diabetes mellitus: An overview onits pharmacological aspects and reported medicinal plants having antidiabetic activity. Asian Pac. J. Trop. Biomed. pp 411-420.

Pugh, D. G. and Baird, N. 2012. Sheep and goat medicine. $2^{\text {nd }}$ Edition. Saunders, Missouri. pp 97-99.

Rucinsky, R., Cook, A., Haley, S., Nelson, R., Zordan, D. L. and Poundstone, M. 2010. AAHA diabetes management guidelines for dogs and cats. J. Am. Anim. Hosp. Assoc. 46(3):215-224.

Shruthi, J. S. 2016. Certain studies on diabetes mellitus in canines M.V.Sc. thesis submitted to karnataka veterinary, animal and fisheries sciences university, Bidar. pp 1-156.

World Health Organisation. 2011. Use of Glycated Hemoglobin (HbA1c) in the Diagnosis of Diabetes Mellitus. Abbreviated Report of a WHO Consultation, 4-25.

\section{How to cite this article:}

Shashi Choudhary, Nazeer Mohammed, Rashmi Singh, Jitendra Kant Nagar, Chanchal Kala, Amit Kumar Meena, Raj Kumar Soni, Praveen Meena and Kiran Choudhary. 2021. Incidence and Clinical Manifestations on Diabetes Mellitus in Canines. Int.J.Curr.Microbiol.App.Sci. 10(07): 655-661. doi: https://doi.org/10.20546/ijcmas.2021.1007.071 